\title{
S urface chemistry of a viscose-based activated carbon cloth modified by treatment with ammonia and steam
}

\author{
J.P. Boudou* \\ CNRS, Université Pierre et Marie Curie, Case 124, LGM, 4 Place Jussieu, 75252 Paris Cedex 05, France
}

\begin{abstract}
The influence of ammonia treatment at $800{ }^{\circ} \mathrm{C}$ on the catalytic activity of a viscose-based activated carbon cloth (ACC) was evaluated for the oxidative retention of $\mathrm{H}_{2} \mathrm{~S}$ or $\mathrm{SO}_{2}$ at room temperature. Change in the surface chemistry was observed by X-ray spectroscopy of nitrogen (N1s) and by temperature programmed desorption (TPD). Dynamic adsorption of $\mathrm{H}_{2} \mathrm{~S}$ or $\mathrm{SO}_{2}$ in moist air onto a packed bed of activated carbon cloth was monitored by measurement of the breakthrough curves at room temperature. ACC modified by ammonia showed noteworthy enhanced $\mathrm{SO}_{2}$ and $\mathrm{H}_{2} \mathrm{~S}$ loading relative to the untreated ACC. Improved $\mathrm{SO}_{2}$ retention rate could be replicated several times after regeneration by washing at room temperature, in contrast to the case with $\mathrm{H}_{2} \mathrm{~S}$. The likely reasons for the behavior of $\mathrm{H}_{2} \mathrm{~S}$ and $\mathrm{SO}_{2}$ on the ammoniatreated ACC are discussed with reference to the recent literature.
\end{abstract}

Keywords: A. Activated carbon, Carbon cloth; B. Surface treatment; D. Catalytic properties, Surface properties

\section{Introduction}

A number of groups have investigated the surface chemistry of $\mathrm{N}$-containing activated carbons as catalysts or catalyst supports for the low temperature oxidation of pollutants in gas or water media. Stohr" et al. [1] have studied the introduction of nitrogen into granulated activated carbon and HOPG graphite powder by ammonia treatment in dry inert atmosphere at $700-900{ }^{\circ} \mathrm{C}$. Nitrogen was chemisorbed in the treatment and XPS showed two N1s signals with binding energies at 401-400 and 399$398 \mathrm{eV}$. When ammonia treatment was performed at mild temperature, the peak at high binding energy (amine groups) was intense compared with the peak at low binding energy (pyridinic groups). At $700{ }^{\circ} \mathrm{C}$, the volume of microand mesopores was unchanged after reaction, while a significant increase of the pore volume in the micropore range and of the apparent surface area was observed in the reaction with ammonia at or above $800{ }^{\circ} \mathrm{C}$. Chemisorbed nitrogen species on the surface of $\mathrm{NH}_{3}$-activated carbon, which would facilitate the dissociative chemisorption of $\mathrm{O}_{2}$

*Tel.: 133-1-4115-5918; fax: 133-1-4427-5141. E-mail address: jpboudou@wanadoo.fr (J.P. Boudou). as superoxide ions, enhanced the surface oxidation of probe molecules such as $\mathrm{H}_{2}$ or aqueous $\mathrm{H}_{2 \mathrm{SO}}$ to $\mathrm{H}_{2} \mathrm{O}$ or $\mathrm{H}_{2} \mathrm{SO}_{4}$, respectively. The catalytic activities were well reproducible after the $\mathrm{NH}_{3}$-activated carbon ageing in air during long-term storage.

Recently, ammonia treatment of activated carbons at high temperature has been used to introduce a high density of surface nitrogen groups on pitch-based and resin-based activated carbon fibers (ACF) to optimize the oxidative retention of up to 5000 ppmv of $\mathrm{SO}_{2}$ in moist air at $20-150^{8} \mathrm{C}$ and atmospheric pressure [2-5]. In spite of a high cost for preparation, several important advantages are imparted to ACFs. Their small external diameters and uniform micropore structure, directly open to the outer surface, confer faster adsorption/desorption kinetics and a lower pressure drop as compared to granular activated carbons. Their fibrous shape permits their use in varieties of easy handling. The woven and knitted forms allow effective and rapid electrical thermal conditioning. ACFs are more suitable for the recovery of sulfuric acid at room temperature than granular activated carbon because the diffusion of sulfuric acid is much easier in the pores of the fiber [6-10]. However, in the case of ACF modified with ammonia and steam, a part of $\mathrm{SO}_{2}$ would remain non- 
desorbable by distilled water extraction at ambient temperature [11].

Within the above scope, the present paper focuses on the ammonia modification of a commercial viscose-based activated carbon cloth (ACC) for the oxidative retention of $\mathrm{H}_{2} \mathrm{~S}$ or $\mathrm{SO}_{2}$ in moist air at room temperature. It combines XPS and XANES to determine nitrogen and sulfur functionalities, TPD to examine the stability of nitrogen and oxygen surface functional groups and adsorption studies to investigate the performance of the adsorbents for the oxidative retention of $\mathrm{SO}_{2}$ and $\mathrm{H}_{2} \mathrm{~S}$.

\section{Experimental}

\subsection{Samples}

The commercial activated carbon cloth used in this study was provided by Actitex (Ref.: WKL20). The sample was selected among a set of Actitex activated carbon cloths for its good mechanical properties and high resistance towards air oxidation at $300{ }^{8} \mathrm{C}$. It was prepared from a viscose rayon cloth (precursor) using a classified method which involves carbonization followed by $\mathrm{CO}_{2}$ activation at $700{ }^{8} \mathrm{C}$. For convenience, the commercial Actitex sample was designated by the code ACC.

In this study, ammonia-steam was preferred to pure ammonia because ammonia treatment using an aqueous solution of ammonia is more straightforward. Yet, this experimental option is not optimal because addition of steam increases pore development and thus micropore widening [12]. Ammonia-steam activation was performed by placing a $0.5-1$-g sample in a quartz tube under flowing nitrogen $\left(100 \mathrm{ml} \mathrm{min}^{21}\right)$ at $800^{8} \mathrm{C}$ during $40 \mathrm{~min}$. The reactor temperature was ramped to $800{ }^{8} \mathrm{C}$, then the input nitrogen line was directed by valve switching to a saturator containing an aqueous solution of $28 \%$ ammonia. The carrier gas line and the saturator were kept at ambient temperature. Isothermal treatment was performed during $40 \mathrm{~min}$. After treatment, the sample was cooled down in a stream of $\mathrm{N}_{2}$. The loss of weight during this process was $13 \mathrm{wt} \%$ daf. The obtained sample was designated by the code ACCN.

\subsection{Porosity values}

The adsorption measurements [13-15] were carried out by a static technique in a high vacuum gravimetric apparatus (McBain balances). Micropore half-width $(x)$ of treated and untreated ACC was calculated from the experimental isotherms using the Dubinin-Radushkevich (DR) equation.

\subsection{TPD $-M S$}

The sample (5-10 mg) was thermal-programmed in
$\mathrm{He} 11 \% \mathrm{Ne}$ at $30 \mathrm{Kmin}^{21}$. Evolved gases were continuously detected with a Leybold quadrupole mass spectrometer. $\mathrm{N}_{2}$ was detected after selective oxidation of $\mathrm{CO}$ to $\mathrm{CO}_{2}$ on $\mathrm{MnO}_{2}$ at $120{ }^{8} \mathrm{C}$. Calibration was done with Air Liquide standard mixtures of the gas to calibrate and pure helium containing $1 \%$ neon-used as an internal standard. Integration of the peaks was computed by using points on either side of a given desorption peak for which the mass spectrometer was at its base line value.

\subsection{XPS}

X-ray photoelectron spectra were measured using a Surface Science Instrument SSX 100 spectrometer with a monochromated Al Ka X-ray source $\left(h n^{5} 1486.6 \mathrm{eV}\right)$, a hemispherical electron analyzer, and a multichannel detector. Carbon fibers were placed in an especially designed support ensuring that no signal was observed from the sample holder. Before each XPS analysis the samples were dried under vacuum at $80{ }^{8} \mathrm{C}$. Samples were then outgassed in the pretreatment chamber at $10^{25}$ Torr prior to transfer to the analysis chamber. The vacuum applied during the measurements was typically less than $5310^{29}$ Torr and data were accumulated in separate regions. The $\mathrm{C} 1 \mathrm{~s}$ peak of the "graphitic" carbon (binding energy, $\mathrm{BE}^{5} 284.6 \mathrm{eV}$ ) was taken as reference in calculating BEs and accounting for charging effects. Data processing was achieved with a Winspec software using a nonlinear, least-squares fitting algorithm and a Shirley baseline. High resolution envelopes were fitted using mixed LorentzianGaussian curves. For all elements, atomic concentrations were estimated based on comparisons of integrated peak intensities normalized by the atomic sensitivity factors. BEs were reproducible to within 0.2 $\mathrm{eV}$.

\subsection{XANES}

Nitrogen K-edge measurements were performed at the Laboratoire pour l'Utilisation du Rayonnement Electromagnetique (LURE, Orsay, France) on the VUV SuperAco storage ring. They were carried out on the Sacemor system connected to the SA72 beam line equipped with a high-energy TGM monochromator (resolution of about 0.2 $\mathrm{eV}$ at the $\mathrm{N} \mathrm{K}$ edge). The spectra were recorded in total electron-yield detection, by dividing the signal by that normalized from the fluctuations in the X-ray intensity of a copper grid freshly coated with gold, simultaneously recorded. They were recorded at normal X-ray incidence (E parallel to the surface). The samples were ground to a very fine particle size, dispersed in acetone, and applied dropwise to high-purity tungsten plates, and the solvent was allowed to evaporate. All measurements were made at room temperature under ultra high vacuum $\left(10^{210}\right.$ Torr). Calibration of the monochromator at the N1s edge was made setting the $\mathrm{N} 1 \mathrm{~s}^{p} *(\mathrm{CN})$ of polyacrylonitrile (PAN, Aldrich) at $401.4 \mathrm{eV}$. 
neon in helium) and calibrated with external gas standards containing $\mathrm{SO}_{2}$ or $\mathrm{HS}$ in helium with $1 \%$ neon.

Sulfur removal was carried out in a fixed bed contained in a micro-column (I.D.: $4 \mathrm{~mm}$ ) surrounded by a tube furnace. The air stream flowing through the fixed bed (inlet at the lower end of the vertical micro-column) contained $\mathrm{H} S \mathrm{~S}$ (5000 ppmv) or $\mathrm{SO}_{2}$ (3000 ppmv) with $75 \%$ water saturation at 25C. The mass of ACC and the total flow rate was about $20 \mathrm{mg}$ and $35 \mathrm{ml} \mathrm{min",} \mathrm{respectively}$ (contact time in weight of sample per gas flow rate was about $0.4 \mathrm{mg} \mathrm{min}$ " $\mathrm{ml}^{*}$ and average residence time in

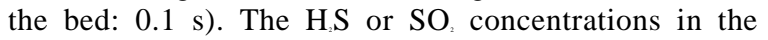
inlet $(C$ ) and outlet $(C)$ gases were continuously detected with a flame photometric detector (FPD). After a protocol recommended by Bagreev et al. [16], before each adsorption experiment, the samples were prehumidified for $2 \mathrm{~h}$ in flowing air with $75 \%$ humidity at room temperature. Adsorption experiments were carried out at room temperature $(25, \mathrm{C})$ and continued until the $\mathrm{H}_{2} \mathrm{~S}$ or $\mathrm{SO}$ concentration in the effluent gas $(C)$ equalled that in the feed stream $(C$.). The first adsorption experiment was performed with the sample as received (without any conditioning). After $\mathrm{H}_{2} \mathrm{~S}$ adsorption, regeneration of the bed was carried out by heating for $10 \mathrm{~min}$ in flowing $\mathrm{N}$ at 500 C. After $\mathrm{SO}_{2}$ adsorption, regeneration was done by washing in a solution of $28 \%$ ammonia in water at room temperature and drying by pressing and flushing with dry helium. Four subsequent adsorption-regeneration experiments were carried out to determine how completely the capacity of the bed could be restored following the regeneration step. The amount of sulfur retained by the active carbon was computed by integration of the breakthrough curve until the breakthrough point corresponding to a de- $\mathrm{SO}_{x}$ ratio $(C / C$ ) of about 0.005 . Retention rate (loading) was expressed in mg of $\mathrm{SO}_{2}$ or $\mathrm{H}_{s}$ per g of dry sample. The relationship between intensity of photon emission from sulfur ( $i_{i}$ ) detected by FPD and the amount of sulfur $(M)$ is given by $i_{\mathrm{s}}: i_{(}(M)^{n}$, where $n$ is close to 1 with experimental conditions used in this study (high $\mathrm{S}$ concentration, low hydrogen flow rate). After desorption under vacuum at $80 \mathrm{C}$ of gases physically adsorbed, the amount of thermal-desorbed $\mathrm{SO}_{2}$ or $\mathrm{HS}$ was determined on the loaded sample for $C / C^{-}{ }^{-} 1$ (steady state) by integration of the TPD-MS signal of the $m / z \quad 64$ and $m / z \quad 34$ fragments. The signal was normalized to $\mathrm{m} / \mathrm{z} 20$ (1\%

T able 1

Selected pore structure parameters (derived from adsorption isotherms of $\mathrm{N}_{z}$ at $77 \mathrm{~K}$, and benzene and $\mathrm{CO}_{z}$ at $298 \mathrm{~K}$ )

\begin{tabular}{|c|c|c|c|c|c|c|c|}
\hline \multirow{2}{*}{$\begin{array}{l}\text { Sample } \\
\text { code }\end{array}$} & \multicolumn{4}{|l|}{ Volume } & \multicolumn{2}{|l|}{ Surface area } & \multirow{2}{*}{$\begin{array}{l}\text { Micropor } \\
\text { e width } \\
2 x \\
(\mathrm{~nm})\end{array}$} \\
\hline & $\begin{array}{l}, \mathrm{nm} \\
V_{\text {sibmic }} \\
\left(\mathrm{cm}^{\circ} \mathrm{g}_{21}\right)\end{array}$ & $\begin{array}{l}0.4-2 \mathrm{~nm} \\
V_{\mathrm{mic}} \\
\left(\mathrm{cm}^{\circ} \mathrm{g}_{21}\right)\end{array}$ & $\begin{array}{l}2-50 \mathrm{~nm} \\
V_{\text {mes }} \\
\left(\mathrm{cm}^{\circ} \mathrm{g}_{21}\right)\end{array}$ & $\begin{array}{l}\text { Gurvich } \\
\text { volume } \\
\left(\mathrm{cm}_{3} \mathrm{~g}_{2}\right)\end{array}$ & $\begin{array}{l}\text { Mesopores } \\
S_{e}: S \quad \text { E } \\
\left(\mathrm{m}_{2} ;\right.\end{array}$ & $\begin{array}{l}\text { Total } \\
\left(\mathrm{m}_{2} \mathrm{~g}_{2}\right)\end{array}$ & \\
\hline$\overline{\mathrm{ACC}}$ & 0.000 & 0.317 & 0.036 & 0.353 & 16.7 & 784 & 0.91 \\
\hline ACCN & 0.000 & 0.472 & 0.046 & 0.518 & 28.5 & 1185 & 1.24 \\
\hline
\end{tabular}

\section{Results and discussion}

\subsection{Pore structure}

Table 1 lists the pore structure parameters. The porous system of the commercial activated cloth (ACC) is mainly composed of a well developed micropore volume, resulting in a BET surface area close to $80{ }_{22} g$. The volume of mesopores is small. Ammonia-steam activation enlarged the pore volume (Gurvich volume over $0.5 \mathrm{~cm}^{*}, S_{\mathrm{BET}}$ close to $1200{ }_{{ }_{2}} \mathrm{~g}^{\prime \prime}$, and the micropore width (from 0.91 to $1.24 \mathrm{~nm}$ ). Burn-off (b.o.) of approximately $13 \%$ obtained after ammonia-steam activation at $800 \mathrm{C}$ during $40 \mathrm{~min}$ is low in comparison with burn-off achieved by steam alone (b.o. of $20 \%$ after a 30 -min soaking time at 700 8C). This low burn-off was explained by Li et al. [5] who showed that ammonia inhibits steam activation. $\mathrm{NH}$ and

$\mathrm{NH}$ radicals formed by $\mathrm{NH}_{3}$ decomposition would quench the active sites formed by reaction of steam with the carbon matrix.

\subsection{Surface groups}

Fig. 1 shows overall XPS spectra and narrow N1s regions for the untreated (ACC) and ammonia treated carbon cloth (ACCN). The survey scan of ACCN indicates introducing surface nitrogen groups readily detected by the N1s peak centred at $400 \mathrm{eV}$. The surface atomic N/C ratio of ACCN (Table 2) could match a tetracyclic aromatic system where one nitrogen atom replaces a carbon atom (e.g. azachrysene or azapyrene). According to Refs. [17-20], the N1s XPS spectra were fitted with four components having mixed Gaussian-Lorentzian peaks with FWHM of $1.8 \mathrm{eV}$ : one pyridinic $\mathrm{N}$ peak at ${ }^{-} 398.3$ $\mathrm{eV}$, one pyrrolic $\mathrm{N}$ peak at $400.1 \mathrm{eV}$, quaternary $\mathrm{N}$ at $401.3 \mathrm{eV}$ and N-oxide at $403.1 \mathrm{eV}$. ACCN XPS displays a dominant zone of 'pyridinic' nitrogen, as confirmed by XANES measurements (Fig. 2). Similar XPS spectra were reported by several authors: Stohr et al. [1] for peat-based activated carbon treated bv ammonia or qualitatively that ammonia treatment was effective in 
(I)

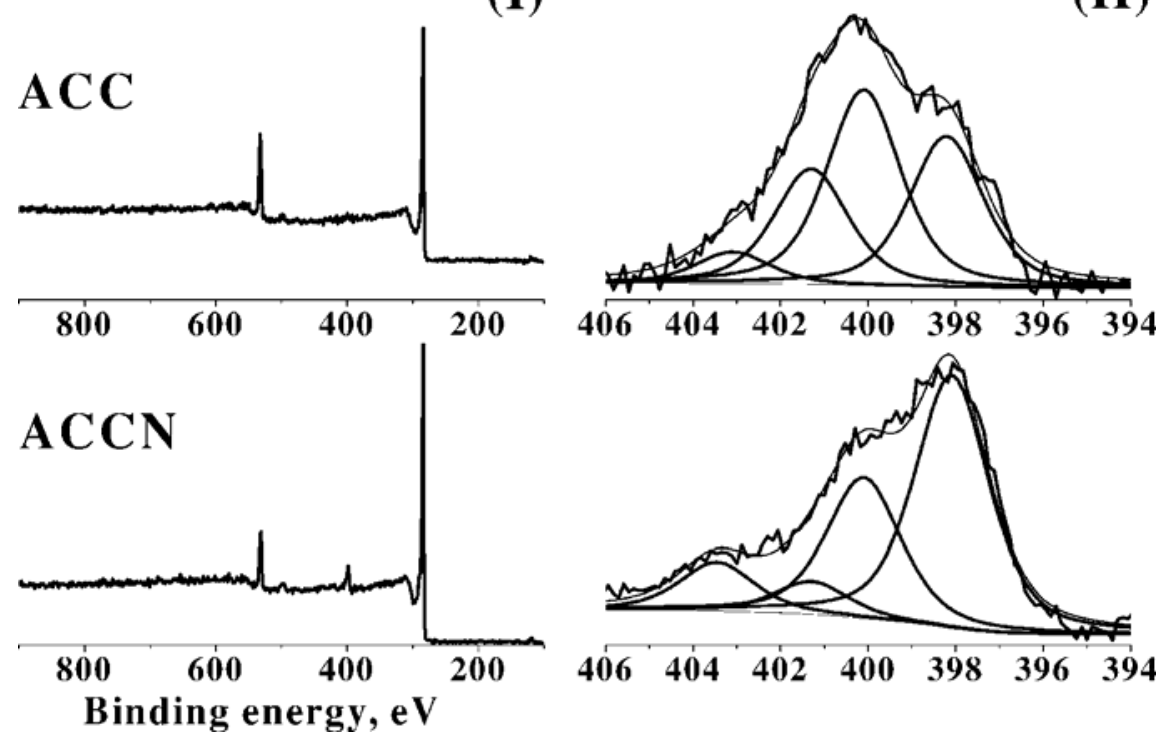

Fig. 1. Overall (I) and N1s (II) XPS spectra obtained for the untreated and ammonia treated activated carbon cloth.

HCN at high temperature, Mangun et al. [3,4] for ACFs produced from steam/ $\mathrm{CO}_{2}$ activated woven phenolic fibers treated with dry ammonia above $700^{8} \mathrm{C}$. They could be assigned to 'pyrrolic' $\mathrm{N}$ or to 'graphitic' $\mathrm{N}$ ( $\mathrm{N}$ in inner position of polyaromatic clusters with circular catenation, as defined by Pels et al. [18] and Casanovas et al. [19]). XANES work in the literature [21] showed the presence of pyridinic and pyrrolic functionalities after ammonia treatment of carbons, and pyridinic, pyrrolic and pyridone functionalities after high temperature oxidation of ammonia treated carbons. The latter may be comparable to the situation described in this paper where ammonia-steam treatment was used. Similar results have been obtained for ammonia treated oxidized carbons. These data support the conclusions from XPS and TPD experiments described in this paper.

In Fig. 3, TPD $\mathrm{N}_{2}$, which evolves at ${ }^{-} 1400 \mathrm{~K}$, appears to be the predominant nitrogen gas. After Ikeda and
Mackie [22], the initial principal nitrogen-containing product of pyrolysis of pyridine (at $1100-1240 \mathrm{~K}$ in a stirred flow reactor) is cyanoacetylene with subsequent elimination of HCN as a secondary product. In the case of carbons, the exact mechanism by which thermal rupture of nitrogen-containing rings occurs has not yet been established. At low heating rate, residence time becomes relatively long, and $\mathrm{N}_{2}$ is supposed to be generated by secondary gas phase reaction of HCN with free radicals and with char- $\mathrm{N}$ [23]. TPD $\mathrm{N}_{2}$ profiles presented in Fig. 3 are the same as those obtained by Stanczyk and Boudou [24] for acridine or carbazole cokes. Thermal treatments during ACC preparation or modification would have removed the small temperature shoulder observed at $1050 \mathrm{~K}$ with the model compounds. The increase of nitrogen emission and the correlated reduction of hydrogen emission, occurring in two peaks centred at 1200 and $1500 \mathrm{~K}$ during ACCN TPD, suggests that $\mathrm{N}$ atoms could

T able 2

XPS atomic N/C ratio (3100) and TPD-MS (from 313 to $1673 \mathrm{~K}$ at $30 \mathrm{Kmin}^{2}$ ) gas yields

\begin{tabular}{|c|c|c|c|c|c|}
\hline \multirow{3}{*}{$\begin{array}{l}\text { Sample } \\
\text { code }\end{array}$} & \multirow{3}{*}{$\begin{array}{l}\text { XPS } \\
N / C_{a}\end{array}$} & \multicolumn{4}{|c|}{ TPD (mmol g $\left.g_{21}\right)$} \\
\hline & & & & $\overline{C n}^{\mathrm{d}}$ & \\
\hline & & $(, 675 \mathrm{~K})$ & (.675 K) & $(, 1250 \mathrm{~K})$ & $(.1250 \mathrm{~K})$ \\
\hline \multirow{2}{*}{$\begin{array}{l}\mathrm{ACC} \\
\mathrm{ACCN}\end{array}$} & 1.59 & 0.29 & 0.15 & 0.98 & 0.56 \\
\hline & 5.69 & 0.01 & 0.04 & 0.28 & 1.23 \\
\hline
\end{tabular}

${ }^{\mathrm{a}}$ Atomic N1s/C1s ratio 310030.595 (instrumental sensitivity factor).

${ }^{\mathrm{b}} \mathrm{CO}_{2}$ as free carboxylic-type $(, 675 \mathrm{~K})$.

${ }^{\mathrm{c}} \mathrm{CO}_{2}$ as lactone-type $(.675 \mathrm{~K}) .{ }^{\mathrm{d}} \mathrm{CO}$

as ketone-type $(, 1250 \mathrm{~K}) .{ }^{\mathrm{e}} \mathrm{CO}$ as

pyrone-type (. $1250 \mathrm{~K})$. 


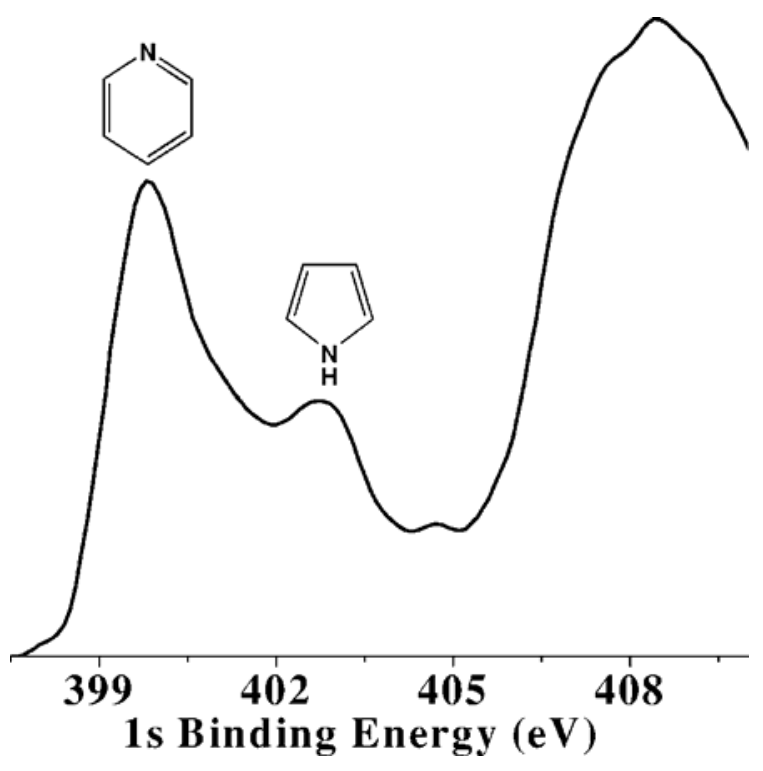

Fig. 2. Nitrogen K edge XANES of the ammonia treated activated carbon cloth (ACCN).

have replaced $\mathrm{CH}$ aromatic groups during attack by $\mathrm{N}$ radicals generated from ammonia at high temperature. Table 2 gives the integrated amounts of thermally desorbed $\mathrm{CO}_{2}$ and $\mathrm{CO}$, expressed as mmol per gram of dry sample. $\mathrm{H}_{2} \mathrm{O}$ was essentially physisorbed. In contrast to the untreated sample (ACC), TPD of the ammonia-steam
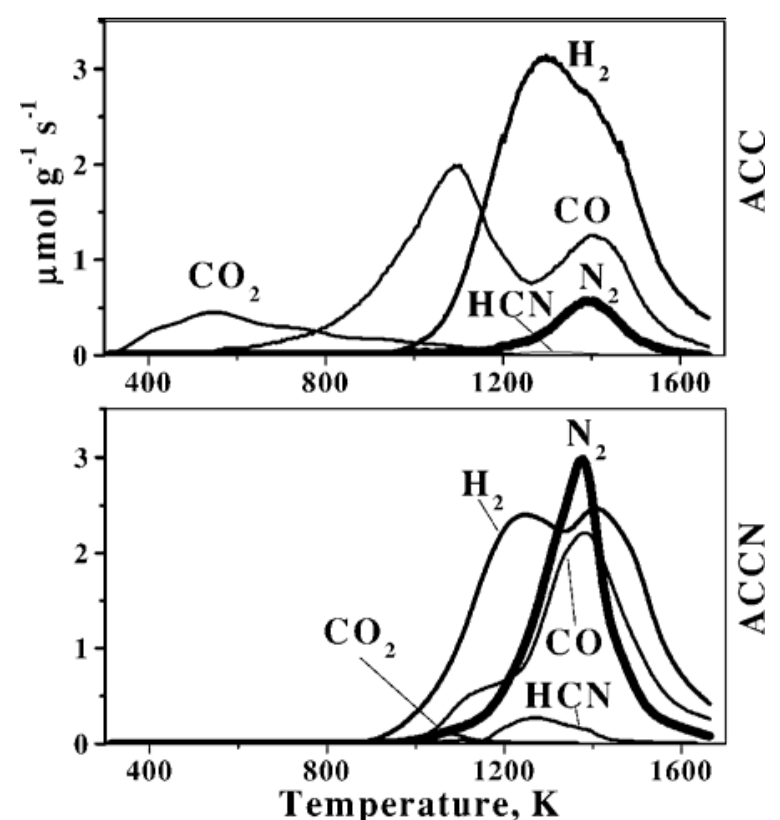

Fig. 3. TPD profiles (from 313 to $1673 \mathrm{~K}$ at $30 \mathrm{Kmin}_{21}$ ) obtained for the untreated and ammonia treated activated carbon cloth. activated sample (ACCN) released a minute amount of $\mathrm{CO}_{2}$ - ascribed to carboxylic acid groups below $675 \mathrm{~K}$, to anhydrides, lactones above $675 \mathrm{~K}$, and a small amount of CO below $1250 \mathrm{~K}$-ascribed to carbonyl groups. Moreover, ammonia treatment increased the evolution rate of CO above $1250 \mathrm{~K}$-ascribed, for simplification, to pyronetype oxygen, though the desorption energy of a CO molecule can depend on the local structure of the oxygen group. Such an increase in CO evolution has already been reported by Papirer et al. [25] who indicated that heat treatment of carbons up to $800{ }^{8} \mathrm{C}$ under $\mathrm{N}_{2}$ leads to the decomposition of acidic groups; when the sample was cooled down in an inert atmosphere and reexposed to air, oxygen was fixed and pyronetype basic groups were formed. Singoredjo et al. [26] found that impregnation of an activated carbon with glucosamine and heating at $1173 \mathrm{~K}$ results in an increase of extremely stable oxygen-containing groups, which can only be desorbed above ${ }^{-} 1400 \mathrm{~K}$. $\mathrm{Li}$ et al. [27] found that there is a directly proportional relationship between the amount of $\mathrm{CO}$ groups evolving above $11000^{8} \mathrm{C}$ and desulfurization activity of ACFs.

\subsection{Breakthrough curves}

The normalized breakthrough curves for $\mathrm{H}_{2} \mathrm{~S}$ and $\mathrm{SO}_{2}$ adsorbed over as-received ACC and the ammonia-modified sample (ACCN) are presented in Fig. 4. Experimental time is expressed as the cumulative amount of $\mathrm{H}_{2} \mathrm{~S}$ or $\mathrm{SO}_{2}$ introduced into the column at constant inlet/outlet pressures, flow rates and inlet concentration $\left(C_{0}: 5000\right.$ ppmv for $\mathrm{H}_{2} \mathrm{~S}$ and 3000 ppmv for $\mathrm{SO}_{2}$ ). This unconventional way to express the time axis enables to read directly the retention rate at the breakthrough point. Compared to Mochida's setup [6], experimental conditions were simplified by using a vertical reactor and low $\mathrm{W} / \mathrm{F}$ ratio to avoid any continuous elution of ${ }_{\mathrm{H} 2 \mathrm{SO}} 4$ out of the fixed bed during adsorption (this enabled us to better compare $\mathrm{H}_{2} \mathrm{~S}$ and $\mathrm{SO}_{2}$ dynamic adsorption). In these conditions, breakthrough curves level off at $C / C_{0} \mid 1$, where $C$ is the outlet concentration. Activated carbon cloth obtained by ammonia-steam activation (ACCN) exhibits enhanced $\mathrm{SO}_{2}$ and $\mathrm{H}_{2} \mathrm{~S}$ retention. However, $\mathrm{H}_{2} \mathrm{~S}$ and $\mathrm{SO}_{2}$ loading dropped substantially after the first thermal regeneration. This drop has already been reported by Bagreev et al. for $\mathrm{H}_{2} \mathrm{~S}$ adsorbed on granulated activated carbons after regeneration by washing [28] or thermooxidative regeneration [29], and by Muniz et al. [2] for $\mathrm{SO}_{2}$ cyclic adsorption-thermal desorption on ammonia treated ACF. The oxidation of the fiber, due to regeneration, could explain the irreversible decrease of the ACF $\mathrm{SO}_{2}$ regeneration ability. The strong increase of $\mathrm{H}_{2} \mathrm{~S}$ loading from the first to the second adsorption steps on the untreated ACC sample could be due to the removal of most acidic groups, which have a negative effect on the dissociation of $\mathrm{H}_{2} \mathrm{~S}$ in the surface water film [30]. In the case of the $\mathrm{N}$ undoped 

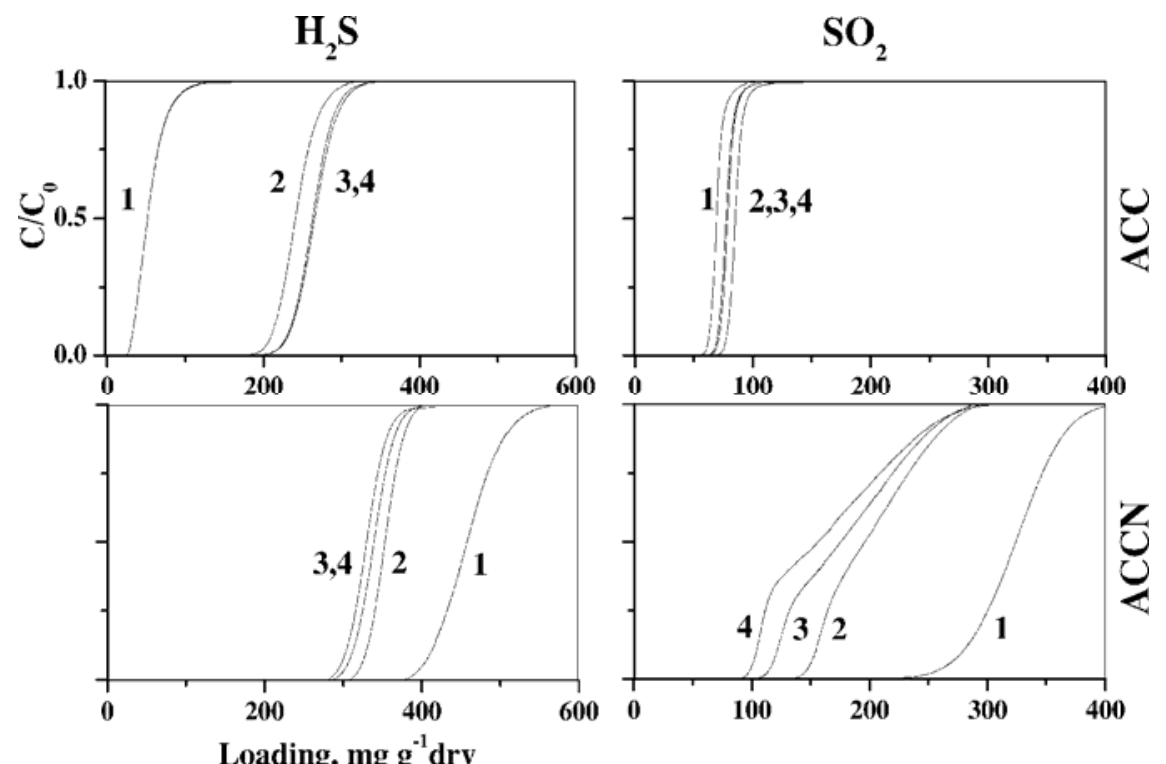

Loading, $\mathrm{mg} \mathrm{g}^{-1}$ dry

Fig. 4. Breakthrough profiles of $\mathrm{H}_{2} \mathrm{~S}(5000 \mathrm{ppmv})$ or $\mathrm{SO}_{2}$ (3000 ppmv) for the untreated or ammonia treated activated carbon cloth. (1-4) Means first to fourth adsorption-thermal regeneration cycle.

ACC, $\mathrm{SO}_{2}$ adsorption is insensitive to the presence of surface acidic groups due to the fact that $\mathrm{SO}_{2}$ is much more soluble in water than $\mathrm{H}_{2} \mathrm{~S}$ in acidic surface $\mathrm{pH}$ range [31].

\subsection{Adsorbed sulfur species}

The XPS S2p signals from the adsorbed sulfur on
ACCN are shown in Fig. 5. By using the energy position of the sulfur 2p signal given by XPS data bank tables of pure reference compounds, it was possible to deconvolute the spectrum from adsorbed sulfur into three doublets (S2p3 /2 and S2p1/2) of mixed Gaussian-Lorentzian lineshape having 2:1 relative intensity and FWHM of $1.8 \mathrm{eV}$ and a maximum at approximately:

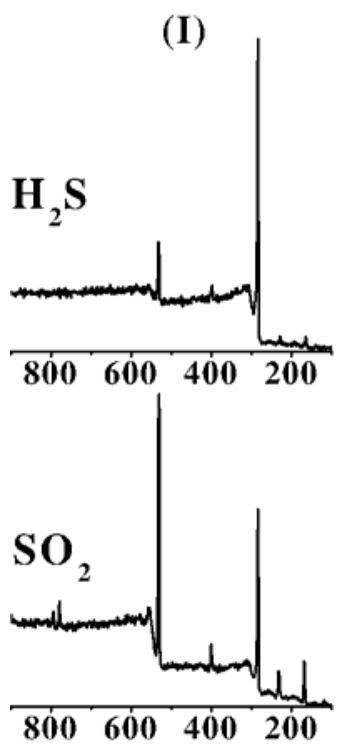

(II)
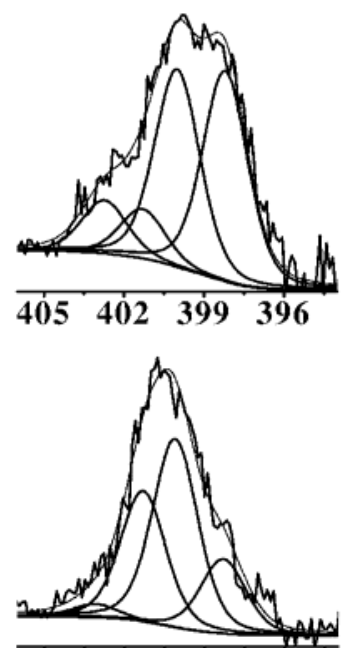

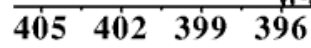

Binding energy, eV
(III)
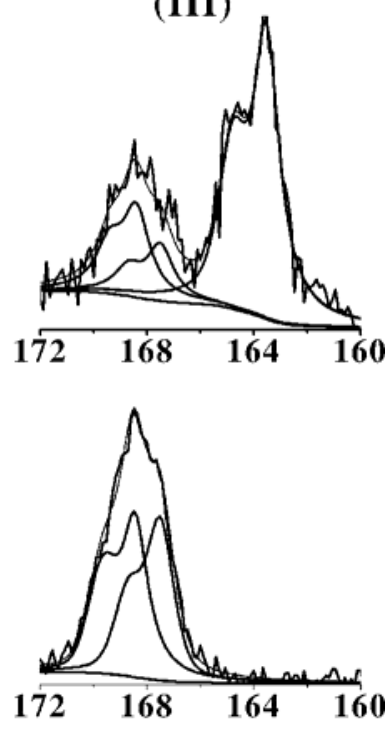

Fig. 5. Overall (I), N1s (II) and S2p (III) XPS spectra for ACCN after adsorption of $\mathrm{H}_{2} \mathrm{~S}$ and $\mathrm{SO}_{2}$. 
1. $\quad 163.5 \mathrm{eV}$ for elemental sulfur $\left(\mathrm{S}_{n}\right)$ and for organic sulfides. After four consecutive $\mathrm{H}_{2} \mathrm{~S}$ adsorptiondesorption-thermal regeneration cycles on ACCN, the proportion of residual sulfur extracted by temperature programmed reduction (TPD at $30 \mathrm{~K} \mathrm{~min}{ }^{21}$ with a carrier gas made of a mixture of $5 \% \mathrm{H}_{2}$ in $\mathrm{He}$ ) was about $40 \%$ of the total adsorbed sulfur. This proportion reached about $60 \%$ for ACC. TPR profiles showed a single $\mathrm{H}_{2} \mathrm{~S}$ peak centred at 930-1000 K which could be assigned to polyaryl sulfides or thiophenes, as well as to polyaryl sulfoxides or sulfones [32,33].

2. $\quad 167.6$ and $168.7 \mathrm{eV}$ for $\mathrm{SO}_{3}$ and $\mathrm{SO}_{4}$ species, respectively. In agreement with XPS, TPD did not show any physisorbed $\mathrm{SO}_{2}$ - as reported by some authors $[34,35]$,indicating that the major part of $\mathrm{SO}_{2}$ was oxidized to $\mathrm{SO}_{3}$ or converted to ${ }_{\text {н2sO4 }}$ by hydration of $\mathrm{SO}_{3}$ after its adsorption. Fig. 5 shows an increase of the $401.2 \mathrm{eV}$ component and an apparent collapse of the pyridine component due to a complexation of $\mathrm{SO}_{3} / \mathrm{SO}_{4}$ with $\mathrm{N}$ surface groups. This change is more pronounced after $\mathrm{SO}_{2}$ than after $\mathrm{H}_{2} \mathrm{~S}$ adsorption. It is well known that when pyridinic $\mathrm{N}$ is involved in adsorption complexes, the N1s core electron can undergo an 11 to $11.7 \mathrm{eV}$ chemical shift, compared to the N1s binding energy for pure pyridine [36-38]. Such an effect of $\mathrm{SO}_{2}$ on the N1s XPS of ammonia-treated ACF has only been reported by one other group [5]. The authors assign the 401.6-eV peak to a conversion of pyridine nitrogen to quaternary nitrogen. Sulfur trioxide is known to be one of the most reactive inorganic compounds; it is an oxidizing agent and a Lewis acid able to combine with free electron pairs of various atoms-in these the donor strength is variable: it reaches its maximum with nitrogen. Otherwise, with excess water $\mathrm{SO}_{3}$ combines vigorously to form sulfuric acid-with less than equimolar amounts of water - polysulfuric acids are formed. Comparison of total sulfur loading with the part of complexed sulfur on nitrogen sites-assuming that there is $1 \mathrm{~mol}$ per nitrogen site-implies a partitioning of sulfur between the carbon surface and the surface nitrogen sites. In the case of $\mathrm{SO}_{2}$ adsorption, the proportion of complexed sulfur on $\mathrm{N}$ sites was appreciably higher than for $\mathrm{H}_{2} \mathrm{~S}$ adsorption. As presented in the next section, study of ACCN activity regeneration showed that sulfur complexation can be reversed by washing/hydrolysis extraction.

\subsection{Regeneration}

By averaging the retention rate of the second, the third and the fourth successive adsorption-thermal-regeneration cycles, one can calculate that $\mathrm{H}_{2} \mathrm{~S}$ retention rate on ACCN was only increased by about $32 \%$ with respect to the untreated sample and by about $71 \%$ for $\mathrm{SO}_{2}$. However, in contrast to $\mathrm{H}_{2} \mathrm{~S}$, thermal regeneration produced a quick

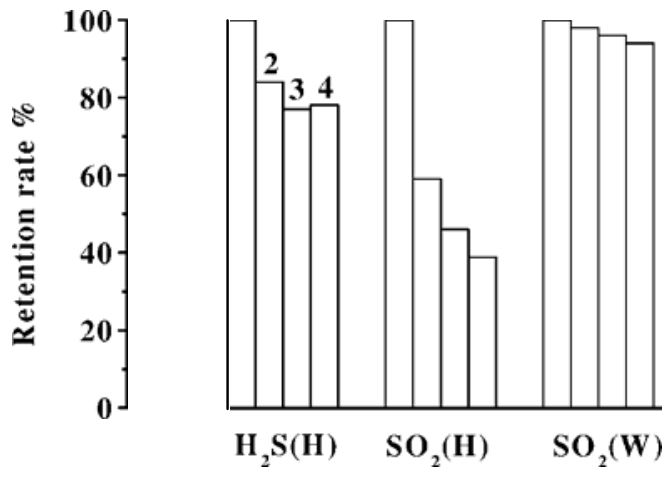

Fig. 6. Normalized retention rate during four consecutive $\mathrm{H}_{2} \mathrm{~S}$ or $\mathrm{SO}_{2}$ adsorption-regeneration cycles on ACCN. (1-4) Means first to fourth adsorption step. $\mathrm{H}$, regeneration by thermal desorption; W, regeneration by washing.

decrease of the oxidative retention for $\mathrm{SO}_{2}$ (Fig. 6). After several consecutive $\mathrm{SO}_{2}$ adsorption-thermal regeneration cycles, TPD of ACCN (Fig. 7) revealed that, contrary to $\mathrm{H}_{2} \mathrm{~S}$, thermal regeneration had not only produced an oxidation of the carbon matrix (introduction of acidic surface groups), but also of the nitrogen aromatic surface groups. When regeneration was performed by washing/ hydrolysis in a solution of $28 \%$ ammonia in water at room temperature, ACCN activity for the oxidative adsorption $\mathrm{SO}_{2}$ was almost completely recovered (Fig. 6) -much less for $\mathrm{H}_{2} \mathrm{~S}$ adsorption. After four consecutive $\mathrm{SO}_{2}$ adsorptionwashing cycles on ACCN, TPD did not release any residual sulfur and showed that the carbon surface had

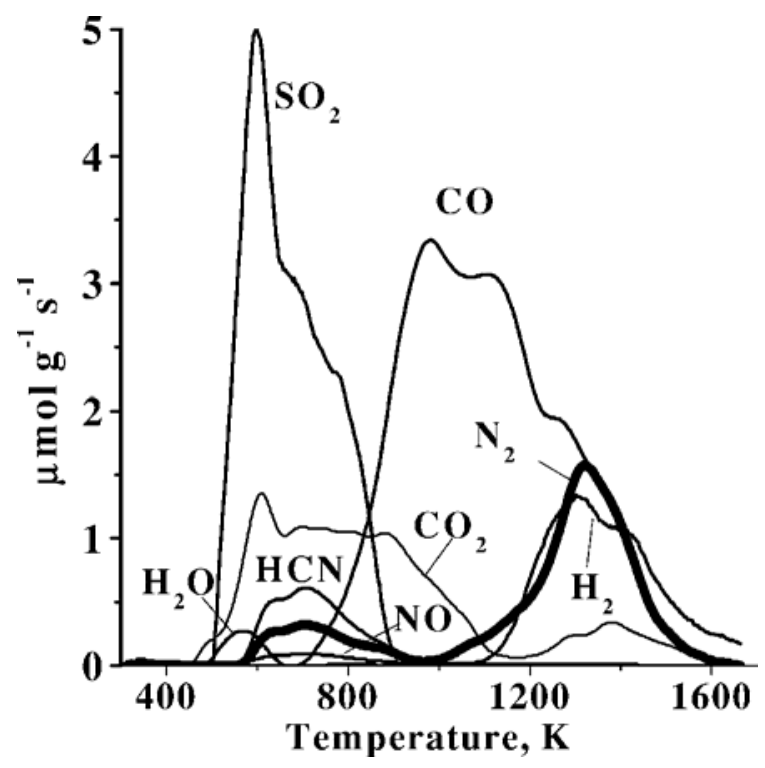

Fig. 7. TPD profiles (from 313 to $1673 \mathrm{~K}$ at 30 Kmin ${ }_{21}$ ) obtained for ACCN after three consecutive $\mathrm{SO}_{2}$ adsorption - thermal regeneration cycles and a fourth adsorption cton 
been only slightly oxidized. In these conditions, the average $\mathrm{SO}_{2}$ retention rate increased by about $350 \%$ with respect to the untreated sample. Compared to $\mathrm{SO}_{2}$, the higher thermal regenerability of $\mathrm{N}$-containing activated carbon after $\mathrm{H}_{2} \mathrm{~S}$ adsorption, is due to a smaller $\mathrm{H}_{2} \mathrm{SO}_{4}$ generation, and the lower efficiency of the $\mathrm{N}$ treatment for $\mathrm{H}_{2} \mathrm{~S}$ adsorption/oxidation can be explained by the fact that elemental sulfur and a substantial amount of water from $\mathrm{H}_{2} \mathrm{~S} / \mathrm{HS}^{2}$ oxidation, as well as $\mathrm{H}_{2} \mathrm{SO}_{4}$ subsequently formed by oxidation of $\mathrm{S}$ to $\mathrm{SO}_{2}$ and $\mathrm{SO}_{2}$ to $\mathrm{SO}_{3}$, remain in the micropores, block the active centres in this region and lower the surface $\mathrm{pH}$ [39]. In the case of $\mathrm{SO}_{2}$, free $\mathrm{H}_{2} \mathrm{SO}_{4}$ tends to be continuously eluted by moist air flowing through the microporous carbon [6].

\section{Conclusions}

Ammonia-steam treatment at $800^{8} \mathrm{C}$ of a viscose-based activated carbon cloth produced a development of porosity at the expense of a slight micropore widening $(1.24 \mathrm{~nm})$. The treatment selectively transformed the surface map of functional groups by introducing a high density of pyridinic-type nitrogen and by thermally desorbing the largest part of acidic oxygen groups, leaving behind some residual basic oxygen groups which generate $\mathrm{CO}$ at high temperature. The results obtained by cyclic adsorptionregeneration on fixed bed show that the ability of the nitrogen-doped ACC to remove $\mathrm{SO}_{2}$ or $\mathrm{H}_{2} \mathrm{~S}$ from moist air at room temperature is clearly enhanced by the following factors affecting its porosity parameters and chemical properties:

- Increase of micropore volume (expressed also by a high BET surface area) without a too large widening of micropores-leading to a decrease of the adsorption energy.

- Removal of most surface acidic groups present on the undoped ACC.

- Increase of surface basic and polar sites: pyridinic groups and pyrone-type groups.

The following differences have been observed between $\mathrm{H}_{2} \mathrm{~S}$ and $\mathrm{SO}_{2}$ adsorption-regeneration:

- Ammonia treatment augmented more strongly the oxidative retention of $\mathrm{SO}_{2}$.

- After desorption of the physisorbed sulfur, XPS measurements showed that sulfite/sulfate and perhaps $\mathrm{SO}_{2}$ form complexes on the nitrogen surface sites.

- Thermal regeneration of the spent ACCN after $\mathrm{SO}_{2}$ adsorption produced a considerable oxidation of the carbon matrix and of the nitrogen sites, while thermal regeneration after $\mathrm{H}_{2} \mathrm{~S}$ adsorption produced a little nxidation
- Regeneration by washing with cold aqueous solution of ammonia - to help decomplexation-removed all sulfur left by $\mathrm{SO}_{2}$ adsorption while insignificant sulfur removal occurred by washing the spent N-doped ACC after $\mathrm{H}_{2} \mathrm{~S}$ adsorption which essentially produces elemental sulfur and organic sulfur covalently bound to the carbon matrix and a small amount of strongly trapped sulfates. In spite of some sulfur complexation, a better mass transfer of the reaction products out of the micropores during adsorption partly accounts for the higher positive influence of the ammonia treatment on the catalytic oxidation of $\mathrm{SO}_{2}$ at room temperature.

\section{A cknowledgements}

Porosity and surface area measurements were performed by Dr T. Siemieniewska and Dr E. Broniek from Wroclaw University (Poland). XPS measurements were performed in collaboration with Dr M. Chehimi and P. Bargiela from ITODYS, University of Paris VII (France). XANES measurements were performed in collaboration with $\mathrm{Dr} \mathrm{Ph}$. Parent and Dr C. Laffon from LURE, University of Orsay (France). We are grateful to Actitex for the gift of samples of activated carbon cloths.

\section{R eferences}

[1] Stohr B, Boehm HP, Schlogl" R. Enhancement of the catalytic activity of activated carbons in oxidation reactions by thermal treatment with ammonia of hydrogen cyanide and observation of a superoxide species as a possible intermediate. Carbon 1991;29(6):707-20.

[2] Muniz J, Herrero JE, Fuertes AB. Treatments to enhance the $\mathrm{SO}_{2}$ capture by activated carbon fibres. Appl Catal B 1998;18(1-2):171-9.

[3] Mangun CL, DeBarr JA, Economy J. Adsorption of sulfur dioxide on ammonia-treated activated carbon fibers. Carbon 2001;39(11):1689-96.

[4] Mangun CL, Benak KR, Economy J, Foster KL. Surface chemistry, pore sizes and adsorption properties of activated carbon fibers and precursors treated with ammonia. Carbon 2001;39(12):1809-20.

[5] Li K, Ling L, Lu C, Qia W, Liu Z, Mochida I. Catalytic removal of $\mathrm{SO}_{2}$ over ammonia-activated carbon fibers. Carbon 2001;39(12):1803-8.

[6] Kisamori S, Kuroda K, Kawano S, Mochida I, Matsumura Y, Yoshikawa M. Oxidative removal of $\mathrm{SO}_{2}$ and recovery of $\mathrm{H}_{2} \mathrm{SO}_{4}$ over poly(acrylonitrile)-based active carbon fiber. Energy Fuels 1994;8(6):1337-40.

[7] Kisamori S, Mochida I, Fujitsu H. Roles of surface oxygen groups on poly(acrylonitrile)-based active carbon fibers in $\mathrm{SO}_{2}$ adsorption. Langmuir 1994;10(6):1241-5.

[8] Mochida I, Kuroda K, Miyamoto S, Sotowa C, Korai Y, Kawano S. et al. Remarkable catalytic activity of calcined pitch based activated carbon fiber for oxidative removal of $\mathrm{SO}_{2}$ as aqueous $\mathrm{H}_{2} \mathrm{SO}_{4}$. Energy Fuels 1997;11(2):272-6. 
[9] Mochida I, Miyamoto S, Kuroda K, Kawano S, Sakanishi K, Korai Y, Yatsutake A, Yoshikawa M. Oxidative fixation of $\mathrm{SO}_{2}$ into aqueous $\mathrm{H}_{2} \mathrm{SO}_{4}$ over a pitch-based active carbon fiber above room temperature. Energy Fuels 1999;13(2):374-8.

[10] M ochida I, Miyamoto S, Kuroda K, Kawano S, Yatsumani S, Korai $\mathrm{Y}$ et al. Adsorption and adsorbed species of $\mathrm{SO}_{2}$ during its removal over pitch-based activated carbon fibers. Energy Fuels 1999;13(2):369-73.

[11]Davini P. Flue gas desulphurization by activated carbon fibers obtained from polyacrylonitrile by-product. Carbon 2003;41(2):277-84.

[12] Tomlinson JB, Freeman JJ, Theocharis CR. The preparation and adsorptive properties of ammonia-activated viscose rayon chars. Carbon 1993;31(1):13-20.

[13] Siemieniewska T, Tomkow K, Kaczmarczyk J, Albiniak A, Grillet Y, Franc ois M. Application of the Dubinin-Astakhov equation to evaluation of benzene and cyclohexane adsorption isotherms on steam gasified humic acids chars from brown coal. Energy Fuels 1990;4(1):61-70.

[14] Siemieniewska T, Tomkow K, Kaczmarczyk J, Albiniak A, Broniek E, Jankowska A et al. Characterization of porous solids III studies. In: Rouquerol J, Rodriguez-Reinoso F, Sing KSW, Unger KK, editors, Surface science and catalysis, vol. 87, Amsterdam: Elsevier; 1994, pp. 695-704.

[15] McEnaney B. Estimation of the dimensions of micropores in active carbons using the Dubinin-Radushkevich equation. Carbon 1987;25(1):69-75.

[16] Bagreev A, Bandosz TJ. $\mathrm{H}_{2} \mathrm{~S}$ adsorption/oxidation on unmodified activated carbons: importance of prehumidification. Carbon 2001;39(15):2303-11.

[17] Stanczyk K, Dziembaj R, Piwowarska Z, Witkowski S. Transformation of nitrogen structures in carbonization of model compounds determined by XPS. Carbon 1995;33(10):1383-92.

[18]Pels JR, Kapteijn F, Moulijn JA, Zhu Q, Thomas KW. Evolution of nitrogen functionalities in carbonaceous materials during pyrolysis. Carbon 1995;33(11):1641-53.

[19] Casanovas J, Ricart JM, Rubio J, Illas F, Jimenez-Mateos $\mathrm{JM}$. Origin of the large N1s binding energy in X-ray photoelectron spectra of calcined carbonaceous materials. J Am Chem Soc 1996;118(34):8071-6.

[20]Kapteijn F, Moulijn JA, Matzner S, Boehm HP. The development of nitrogen functionality in model chars during gasification in $\mathrm{CO}_{2}$ and $\mathrm{O}_{2}$. Carbon 1999;37(7):1143-50.

[21] Jia YF, Xiao B, Thomas KM. Adsorption of metal ions on nitrogen surface functional groups in activated carbons. Langmuir 2002;18(2):470-8.

[22] Ikeda E, Mackie JC. Thermal decomposition of two coal model compounds-pyridine and 2-picoline. Kinetics and product distributions. J Anal Appl Pyrolysis 1995;34(1):4763

[23] Kidena K, Hirose Y, Aibara T, Murata S, Nomura M. Analysis of nitrogen-containing species during pyrolysis of coal at two different heating rates. Energy Fuel 2000;14(1):184-9.
[25] Stanczyk K, Boudou JP. Elimination of nitrogen from coal in pyrolysis and hydropyrolysis: a study of coal and model chars. Fuel 1994;73(6):940-4.

[26] Papirer E, Li S, Donnet JB. Contribution to the study of basic surface groups on carbons. Carbon 1987;25(2):243-7.

[27] Singoredjo L, Kapteijn F, Moulijn JA, Martin-Martinez JM, Boehm HP. Modified activated carbons for the selective catalytic reduction of $\mathrm{NO}$ with $\mathrm{NH}_{3}$. Carbon 1993;31(1):213-22.

[28] Li K, Ling L, Lu C, Liu Z, Liu L, Mochida I. Influence of COevolving groups on the activity of activated carbon fiber for $\mathrm{SO}_{2}$ removal. Fuel Process Technol 2001;70(3):151-8.

[29]Bagreev A, Rahman H, Bandosz TJ. Study of $\mathrm{H}_{2} \mathrm{~S}$ adsorption and water regeneration of spent coconut-based activated carbon. Environ Sci Technol 2000;34(21):458792.

[30]Bagreev A, Rahman H, Bandosz TJ. Thermal regeneration of a spent activated carbon previously used as hydrogen sulfide adsorbent. Carbon 2001;39(9):1319-26.

[31]Bagreev A, Adib F, Bandosz TJ. pH of activated carbon surface as an indication of its suitability for $\mathrm{H}_{2} \mathrm{~S}$ removal from moist air streams. Carbon 2001;39(12):1897-905.

[32]Boniface J, Shi Q, Li YQ, Cheung JL, Rattigan OV Davidovits $\mathrm{P}$ et al. Uptake of gas-phase $\mathrm{SO}_{2}, \mathrm{H}_{2} \mathrm{~S}$, and $\mathrm{CO}_{2}$ by aqueous solutions. J Phys Chem A 2000;104(32):750210.

[33] Kozlowski M, Wachowska H, Yperman J, Franco DV, Mullens J, van Poucke LC. Atmospheric-pressure temperature-programmed reduction study of high-sulfur coals reduced in a potassium/liquid ammonia system. Energy Fuels 1998;12(6):1142-7.

[34] Van Aelst J, Yperman J, Franco DV, van Poucke LC, Buchanan AC, Britt PF. Study of silica-immobilized sulfur model compounds as calibrants for the AP-TPR study of oxidized coal samples. Energy Fuels 2000;14(5):1002-8.

[35] Raymundo-Pinero E, Cazorla-Amoros D, Linares-Solano A. Temperature programmed desorption study on the mechanism of $\mathrm{SO}_{2}$ oxidation by activated carbon and activated carbon fibres. Carbon 2001;39(2):231-42.

[36] Bagreev A, Bashkova S, Bandosz TJ. Adsorption of $\mathrm{SO}_{2}$ on activated carbons: the effect of nitrogen functionality and pore sizes. Langmuir 2002;18(4):1257-64.

[37]Borade R, Sayari A, Adnot A, Kaliaguine S. Characterization of acidity in ZSM-5 zeolites: an X-ray photoelectron and IR spectroscopy study. J Phys Chem 1990;94(15):5989-94.

[38]Huang M, Adnot A, Kaliaguine S. Cation-framework interaction in alkali-cation-exchanged zeolites: an XPS study. J Am Chem Soc 1992;114(25):10005-10.

[39] Chehimi MM, Watts JF, Jenkins SN, Castle JE. X-ray photoelectron spectroscopy investigation of acid-base interactions in adhesion. Part 1. Estimation of polymer properties by a solvent swelling technique. J Mater Chem 1992;2(2):209-15

[40] Adib F, Bagreev A, Bandosz TJ. Adsorption/oxidation of hydrogen sulfide on nitrogen-containing activated carbons. Langmuir 2000;16(4):1980-6. 